\title{
Down-regulation of A-FABP predicts non- muscle invasive bladder cancer progression: investigation with a long term clinical follow-up
}

Christel Mathis ${ }^{1}$, Isabelle Lascombe ${ }^{2}$, Franck Monnien ${ }^{1}$, Hugues Bittard ${ }^{2,3}$, François Kleinclauss ${ }^{3}$, Isabelle Bedgedjian ${ }^{1}$, Sylvie Fauconnet ${ }^{2,3^{*+}}$ and Séverine Valmary-Degano ${ }^{1,2^{*+}}$

\begin{abstract}
Background: Non-muscle invasive bladder cancers (NMIBC: pTa, pT1) are characterised by a high risk of recurrence and/or progression. Identification of prognostic markers is needed to improve both diagnosis and management of the disease. The aim of this study was to analyse the expression of A-FABP (adipocyte-fatty acid binding protein) and to evaluate its prognostic value in bladder cancer with a long term clinical follow-up.

Methods: A-FABP expression was investigated by immunohistochemistry in 236 tumours (114 pTa, 61 pT1, 61 pT2-4). Immunostaining was classified as negative (absent or weak immunostaining and moderate or strong staining on $\leq 10 \%$ of cells) or positive (moderate or strong staining on $>10 \%$ of cells). Event-free survival (EFS) and overall survival (OS) were determined with a 87.3 months median follow-up in the overall cohort.

Recurrence-free survival (RFS) and progression-free survival (PFS) were established in NMIBC.

Results: Loss of A-FABP was associated with higher mean age, high stage/grade, and the presence of metastatic lymph nodes. It was correlated with shorter median EFS (17.5 vs 62.5 months; $p=0.001)$ and mean OS (76.7 vs 154.2 months; $p=0.009$ ) and with higher risk of progression in the $\mathrm{pTa} / \mathrm{pT} 1$ subgroup (HR, 0.36; $95 \% \mathrm{Cl}$, $0.13-0.96 ; p=0.041)$ and importantly in the pTa tumours ( $H R, 0.34 ; 95 \% \mathrm{Cl}, 0.10-0.97 ; p=0.045)$.

Conclusion: These results demonstrated that loss of A-FABP expression following a long follow-up was predictive of pTa and pTa/pT1 progression. Immunohistochemistry on diagnostic biopsy is easy to use and could be of value to help clinicians to propose appropriate treatment for these tumours.
\end{abstract}

Keywords: Bladder cancer, A-FABP, FABP4, Adipocyte-fatty acid binding protein, Prognostic marker

\footnotetext{
*Correspondence: sylvie.fauconnet@univ-fcomte.fr; svalmarydegano@chugrenoble.fr

${ }^{\dagger}$ Sylvie Fauconnet and Séverine Valmary-Degano contributed equally to this work.

University Bourgogne Franche-Comté, EA3181, LabEx LipSTIC

ANR-11-LABX-0021, F-25030 Besançon, France

'Department of Pathology, University Hospital of Besançon, F-25000

Besançon, France

Full list of author information is available at the end of the article
}

(c) The Author(s). 2018 Open Access This article is distributed under the terms of the Creative Commons Attribution 4.0 International License (http://creativecommons.org/licenses/by/4.0/), which permits unrestricted use, distribution, and reproduction in any medium, provided you give appropriate credit to the original author(s) and the source, provide a link to the Creative Commons license, and indicate if changes were made. The Creative Commons Public Domain Dedication waiver (http://creativecommons.org/publicdomain/zero/1.0/) applies to the data made available in this article, unless otherwise stated. 


\section{Background}

Bladder cancer is a significant cause of morbidity and mortality worldwide with about 430,000 new cases diagnosed in 2012. In the European population, it represents $4 \%$ of all cancers with 151,297 new cases and 52,411 deaths in 2012 [1]. Over 90\% of bladder cancers are urothelial carcinoma (UC) [2]. At diagnosis, 75\% are non-muscle invasive bladder cancers (NMIBC). They include carcinoma in situ (Cis) and papillary tumours confined to the mucosa ( $\mathrm{pTa}$ ) or lamina propria (pT1). The remaining $25 \%$ are muscle-invasive bladder cancers (MIBC, $\geq \mathrm{pT} 2$ ) [3]. In the NMIBC patient group, as many as 50 to $80 \%$ of cases with low grade pTa-pT1 will recur, and up to 40 to $50 \%$ of cases with high grade/G3 pTa-pT1 or associated Cis will progress within 5 years to a higher tumour stage or metastatic disease [4]. The treatment of NMIBC involves transurethral resection associated or not with intravesical therapy [5]. Progression to (or at initial diagnosis presentation with) MIBC represents a critical step in disease progression. MIBC have a poorer prognosis, since $50 \%$ of patients will relapse with metastasis development within 2 years despite optimal therapy [6]. Standard therapy of organ-confined MIBC includes radical cystectomy or chemoradiotherapy [7]. Patients with bladder urothelial carcinoma should be carefully monitored for signs of disease recurrence or progression. The predictive ability of conventional clinical and pathological parameters is limited. To date, there are no established biomarkers that are able to forecast progression. Therefore, molecular prognostic markers of tumour recurrence and progression are urgently needed to improve our understanding, diagnosis and management of UC.

Several studies have reported the involvement of fatty acid binding proteins (FABPs) in the progression of different cancer types such as pancreas, breast, colorectal and renal cancers, and melanoma [8-13]. Nevertheless, the relationship between the expression pattern of the different FABPs in human cancer tissues and their role in cancer development is unclear. FABPs are lipid carriers involved in secretion, uptake and intracellular fatty acid transport to subcellular organelles such as mitochondria and peroxisomes [14]. They are implicated in glucose metabolism and lipid oxidation [15]. Adipocyte-FABP (A-FABP/FABP4/aP2) is an adipokine that binds hydrophobic ligands such as saturated or unsaturated long-chain fatty acids. It is highly expressed in adipocytes and macrophages, and has been linked to the development of insulin resistance, metabolic syndrome and atherosclerosis [16]. In addition, this protein works as a cytoplasmic shuttle protein for ligand activation of the nuclear receptor PPAR $\gamma$ to activate its downstream transcriptional targets involved in cellular differentiation, apoptosis and anti-inflammatory responses [17]. The exact function of this protein in cancer is still controversial. A-FABP implication has been explored in breast cancer $[18,19]$, ovarian cancer [20, 21], oral squamous cell cancer [22], and non-small cell lung cancer [23]. Few studies have investigated the expression of A-FABP in bladder cancer. This protein is highly expressed in normal urothelium [24, 25]. Proteomic analysis of protein expression profiles of bladder UC has highlighted a loss or decrease of A-FABP in high-grade/stage lesions compared with low-grade/stage tumours $[24,26]$. The loss of A-FABP protein [25] or mRNA expression [27] has been associated with bladder cancer progression. However, in these studies, no data were available on patient follow-up.

The purposes of the present work were firstly, to study by immunohistochemistry the expression of A-FABP according to clinical and pathological parameters, and secondly, to evaluate its prognostic value in a cohort of 236 UC with a long follow-up. In particular, we investigated whether this protein could be a prognostic marker of recurrence or progression of $\mathrm{pTa} / \mathrm{pT} 1 \mathrm{UC}$.

\section{Methods}

Patient material

All primary UC diagnosed on transurethral resection of bladder tumours (TURB) in the Department of Pathology, Jean Minjoz University Hospital (Besançon, France) from 1 January 2000 through 31 December 2009 were eligible for inclusion in this retrospective study. We included all initial diagnoses of bladder UC from pTa to pT4 of any grade, before any treatment, a total of 274 patients. We excluded kidney, prostate or ureter cancers associated with bladder cancer. We also excluded patients without clinical information or usable samples (tissue bloc fully utilised and two negative internal controls). The medical records of all patients included were checked up to 15 May 2017 to determine follow-up. All living patients were informed of the study in writing and their consent was obtained. Tumour recurrence was defined as the reappearance of UC at a lower or equivalent pathological stage after completion of TURB. Tumour progression was characterised by a recurrence of disease with higher grade, stage or metastatic status.

\section{Cell lines and culture}

The human cervical carcinoma cell lines HeLa, Ca Ski, C-33 A and the human bladder cancer cell line RT4 were obtained from ATCC (Rockville, MD, USA). Cells were maintained in DMEM (HeLa, Ca Ski), EMEM (C-33 A) or McCoy's 5A medium (RT4) supplemented with $10 \%$ fetal calf serum (FCS) (Lonza, Basel, Switzerland), 1\% antibiotic antimycotic mixture $(100 \mu \mathrm{g} / \mathrm{ml}$ streptomycin, $100 \mathrm{U} / \mathrm{ml}$ penicillin, $25 \mu \mathrm{g} / \mathrm{ml}$ amphotericin B), $2 \mathrm{mM}$ glutamine and 
$15 \mathrm{mM}$ Hepes (Sigma-Aldrich, Saint Quentin Fallavier, France) at $37^{\circ} \mathrm{C}$ in a humidified $5 \% \mathrm{CO}_{2}, 95 \% \mathrm{O}_{2}$ air incubator.

\section{Protein extraction and western blotting analysis}

Cells were washed with cold PBS $1 \mathrm{X}$ and scraped in RIPA lysis buffer (50 mM Tris- $\mathrm{HCl} \mathrm{pH} 7.4,0.1 \%$ SDS, $150 \mathrm{mM} \mathrm{NaCl}, 1 \mathrm{mM}$ EDTA, $1 \%$ Nonidet P-40, 0.5\% sodium desoxycholate) supplemented with protease inhibitors (Roche Diagnostics, Meylan, France). Whole cell lysates were then sonicated and centrifuged at 10000 rpm for $10 \mathrm{~min}$ at $4{ }^{\circ} \mathrm{C}$. Protein concentration was estimated using the Bradford protein assay (Bio-Rad, Marnes-la-Coquette, France). Total protein extracts $(30 \mu \mathrm{g})$ were dissolved in Laemmli buffer (Bio-Rad) and separated by $15 \%$ SDS-PAGE. Proteins were transferred onto PVDF membranes (GE Healthcare, Amersham, UK) and non-specific binding was blocked in TBSTween 20 buffer $(0.5 \mathrm{mM}$ Tris- $\mathrm{HCl}, 45 \mathrm{mM} \mathrm{NaCl}, 0.05 \%$ Tween 20, pH 7.4) containing 5\% nonfat milk. Membranes were incubated with the primary antibody anti-A-FABP (clone AB13979, 1:1000, Abcam, Paris, France). Protein blots were probed with anti- $\beta$-actin (clone AC-15, 1:40000, Sigma-Aldrich) as controls for protein loading. Bound primary antibody was detected using an HRP-conjugated secondary antibody anti-rabbit IgG (1:5000 or 1:10000) obtained from BD Biosciences (Le Pont de Claix, France). Proteins were visualised using an enhanced chemiluminescence detection method (GE Healthcare) followed by film exposure (Hyperfilm ECL, GE Healthcare), or by using ChemiDoc XRS+ with Image Lab Software (Bio-Rad).

\section{Immunohistochemistry}

Tissue samples, obtained after TURB, were fixed in $4 \%$ formalin and paraffin embedded. Blocks were cut serially at $3 \mu \mathrm{m}$ thickness, deparaffinised in toluene, and rehydrated in graded ethanol. Antigen retrieval was performed by using $0.5 \% \mathrm{H}_{2} \mathrm{O}_{2}$ for $30 \mathrm{~min}$, followed by unmasking in citrate buffer ( $\mathrm{pH}$ 6.0) for $20 \mathrm{~min}$ at high temperature, and then blocked with $0.5 \%$ bovine serum albumin (BSA). Sections were incubated with the A-FABP primary antibody (rabbit anti-human FABP4; dilution 1:1500; Abcam ab13979) for one hour at room temperature using the automated IHC/ISH slide staining BenchMark XT instrument (Roche Diagnostics) according to the manufacturer's instructions. After washing, the slides were incubated for 30 min with the ImmPRESS ${ }^{\text {Tw }}$ HRP Universal Antibody (anti-mouse IgG/anti-rabbit IgG, peroxidase) (Vector Laboratories, CliniSciences, Nanterre, France). Endogenous peroxidase activity was removed by dipping the sections in $5 \%$ hydrogen peroxide for $10 \mathrm{~min}$ at room temperature followed by incubation with streptavidin-horseradish peroxidase for $25 \mathrm{~min}$. Finally, peroxidase activity was revealed by DAB (3,3'-diaminobenzidine) staining (0.9 $\mathrm{mg} / \mathrm{mL}$ ) for $7 \mathrm{~min}$. Sections were counterstained with Harris haematoxylin/eosine/safran (HES) with Leica Autostainer XL (Leica Biosystems, Nanterre, France), dehydrated in alcohol, and mounted using a standard procedure. Negative controls were obtained by omitting the first antibody. Normal bladder specimens were obtained from patients who had undergone cystoprostatectomy for prostate carcinoma. For immunocytochemistry analysis, RT4 and Ca Ski cells were fixed with formalin, paraffin-embedded and processed as described above. The status of A-FABP was assessed in a coded manner by a pathologist without knowledge of the clinical or pathological features of the patient. For each section, the presence of A-FABP immunostaining in endothelial cells was checked as an internal control. The proportion of stained cells, the cellular localisation of immunostaining (nuclear, cytoplasmic, or both), the intensity and different types of staining (basal cells only; one-third, two-thirds or the entire height of the urothelium and/or patchy staining) were used as criteria of evaluation. A-FABP staining was considered positive when $>10 \%$ of cells were moderately or strongly stained, and negative when staining was weak or when $\leq 10 \%$ of cells were moderately or strongly stained.

\section{Statistical analysis}

We used the mean ( \pm standard deviation) values and frequencies (percentages) for the description of continuous and categorical variables, respectively. Means and proportions were compared using Student's $t$ test and the chi-squared test (or Fisher's exact test, if appropriate), respectively.

Event-free survival (EFS) was calculated from the date of TURB to the date of the first recurrence, progression or death from any cause. If no event was observed, patients were censored at the last follow-up. Overall survival (OS) was defined as the time between the date of TURB and the date of last follow-up or the date of death from any cause. Recurrence-free survival (RFS) and progression-free survival (PFS) were defined as the time between the date of TURB and the date of the first tumour recurrence or tumour progression, respectively. Survival curves were built using the Kaplan-Meier method and compared using the log-rank test. Survivals were described as median with $95 \%$ confidence intervals (CI) for PFS, and OS or hazard ratio (HR) with 95\% CI for RFS and PFS when medians were not reached. For EFS and OS, all variables with $p<0.05$ observed in univariate survival analysis were included in a multivariate Cox regression model with stepwise backward elimination to estimate HR with a $95 \% \mathrm{CI}$ and to select potential prognostic factors. Follow-up was calculated using reverse Kaplan-Meier estimation. All statistical tests were 2 -sided and probability values $<0.05$ were regarded 
as significant. Analyses were performed with SPSS 20 software (IBM).

\section{Results}

\section{Patient characteristics}

A consecutive series of 236 patients was investigated, including 192 men (81.4\%) and 44 women (18.6\%) with a sex ratio of 4.4. The mean age was 70.45 years (median 72 , range 25-99) with a standard deviation of 13.3 years. Two pathologists reclassified all tumours from the old to the new 2004 WHO consensus classification to establish the following cohort: $114 \mathrm{pTa}$ (25 papillary urothelial neoplasms of low malignant potential (PUNLMP), 69 low grade UC (LG-UC) and 20 high grade UC (HG-UC)), 61 pT1 (7 LG-UC and 54 HG-UC), and 61 pT2-4 (HG-UC). The subtype of 215 (91.1\%) tumours was the common papillary histological type. The other subtypes were represented by UC with squamous, glandular, or neuroendocrine differentiation, as well as the micropapillary, reversed, and sarcomatoid variants. UC-associated carcinoma in situ was noted in 9/236 (3.8\%) of pathological reports.

\section{Validation of a human anti-A-FABP specific antibody} Immunoblotting experiments were performed with total protein extracts from A-FABP-positive or -negative cancer cell lines. The Abcam human A-FABP antibody did not exhibit any aspecific hybridisation (Fig. 1a). It detected an A-FABP band of approximately $14 \mathrm{kDa}$ size in the RT4 bladder cancer cell line (derived from a well-differentiated low grade papillary tumour) used as a positive control, as we have previously shown with a mouse A-FABP antibody [27]. On the other hand, the protein was not found in HeLa, Ca Ski and C-33 A cervical cancer cells. We showed by immunocytochemistry that A-FABP was present in RT4 cells and absent in $\mathrm{Ca}$ Ski cells, confirming the results obtained by western blotting. As expected, immunohistochemistry revealed that A-FABP was highly expressed in adipose tissue but was absent in cervical cancer specimens (Fig. 1b). These results validated the relevance of the choice of human A-FABP antibody.

\section{Histological analysis of human bladder biopsy samples and immunohistochemical evaluation of A-FABP expression}

The expression pattern of A-FABP was analysed by immunohistochemistry on 236 tumour sections. The baseline characteristics of the patients are described in Table 1. Morphological analysis was performed on paraffin-embedded bladder biopsy tissue sections stained with haematoxylin and eosin (H\&E). Healthy bladder tissue was used as positive control (Fig. 2a). The histology of the bladder tumours was clearly different from healthy bladder tissue. Papillary tumours are defined by the presence of true papillae with central fibrovascular cores covered by neoplastic epithelium. At low grade, there is a generally ordered architectural appearance to the cells within the epithelium with an impression of increased cellularity and increased nuclear density (Fig. $2 \mathrm{~b})$. The nuclei tend to be uniformly enlarged and retain the elongated to oval shape of normal urothelial cells, and the chromatin remains fine with small and generally inconspicuous nucleoli. At high grade, the papillae are frequently fused, forming apparently solid masses. The overall impression is one of disordered growth. The epithelium is of variable thickness. Individual and discohesive cells are haphazardly arranged within the epithelium. Nuclei are hyperchromatic and pleomorphic. The chromatin is dense, irregularly distributed and often clumped, while the nucleoli may be single or multiple and are often prominent. These characteristics are

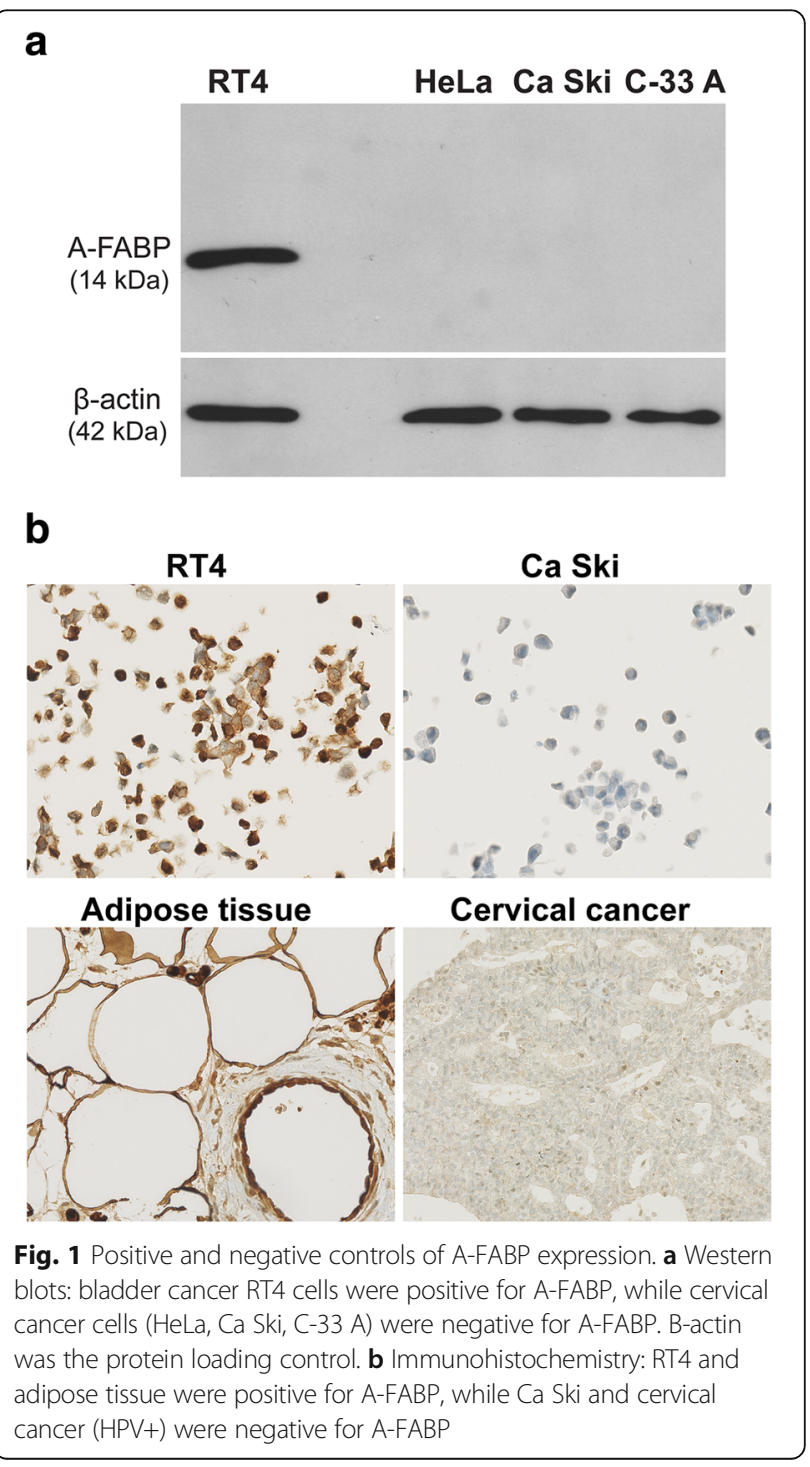


Table 1 Clinicopathological data according to A-FABP expression

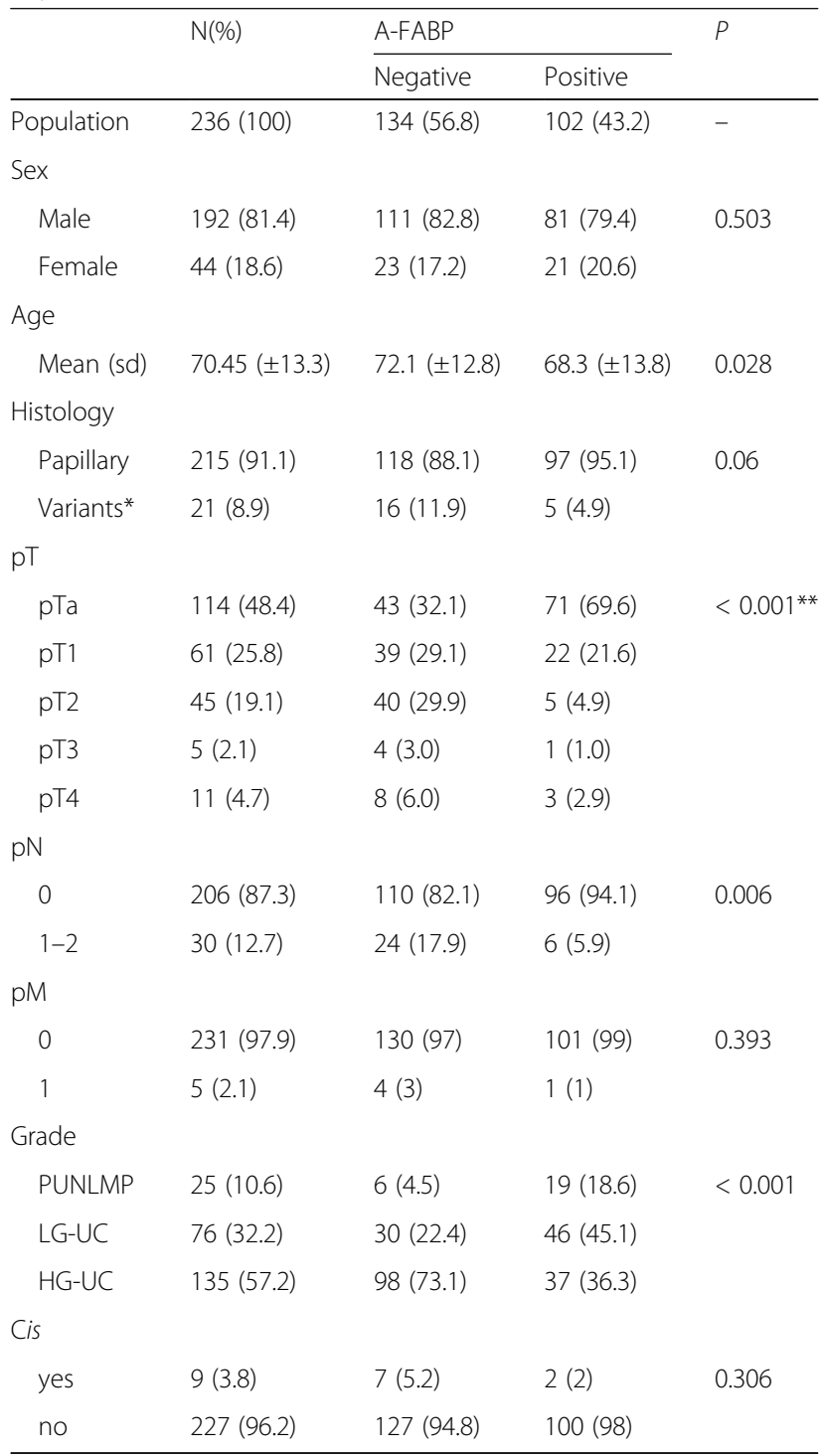

*The histological variants include micropapillary, nested, reversed and sarcomatoid variants, urothelial carcinoma with squamous, glandular or neuroendocrine differentiation

${ }^{*}$ Due to some reduced numbers, the pT3 and pT4 stages were grouped together with the pT2 stage for the Khi-2 test

Abbreviations: PUNLMP Papillary urothelial neoplasm of low malignant potential, LG-UC Low grade urothelial carcinoma, HG-UC High grade urothelial carcinoma, Cis Carcinoma in situ

illustrated in Fig. 2c and d, corresponding to papillae from $\mathrm{pT} 1$ and an infiltrating contingent from pT3 UC, respectively. By immunohistochemistry, intense nuclear and/or cytoplasmic A-FABP staining was observed in the entire height of the normal urothelium (Fig. 2e). Of 236 UC specimens examined in this study, 102 (43.2\%) were positive for A-FABP and 134 (56.8\%) were negative. Of the 134 specimens considered as negative, $69(51.5 \%)$ were totally negative, while 65 specimens $(48.5 \%)$ displayed moderate or strong but patchy positive staining of less than $10 \%$ of tumour cells. Figure 2 illustrates different examples of immunostaining: a pTa UC with intense staining of more than $10 \%$ of tumour cells (Fig. 2f), a pT1 UC with heterogeneous staining of more than $10 \%$ of tumour cells (Fig. 2g), and a pT2 UC that was negative for A-FABP (Fig. 2h). Concerning the immunostaining pattern, A-FABP staining was strong and both nuclear and cytoplasmic in most cases (85.3 and 83.8\%, respectively). We also studied the heterogeneity of the immunostaining as follows: absent, patchy, basal cell layer only, one-third, two-thirds, or the entire height of the urothelium. A-FABP positive tumours could simultaneously express different types of staining in the studied area. But in most cases, the entire height of the urothelium (68.6\% UC) was involved and staining was patchy $(62.7 \% \mathrm{UC})$.

\section{Association between A-FABP expression and clinicopathological data}

Potential associations between A-FABP expression and clinicopathological features were investigated. As shown in Table 1, among A-FABP-positive tumours, strong immunoreactivity was detected in pTa specimens. Indeed, of 102 A-FABP-positive cases, 71 (69.6\%) were pTa, 22 (21.6\%) were pT1, 5 (4.9\%) were pT2, 1 was pT3 (1\%) and $3(2.9 \%)$ were pT4. Statistical analysis revealed a significant association between loss of A-FABP expression and tumour stage $(p<0.001)$. Concerning histological grade, in the A-FABP-positive subgroup, 19 (18.6\%) were PUNLMP, 46 (45.1\%) were LG-UC, and 37 (36.3\%) were HG-UC. In the A-FABP-negative subgroup, 6 (4.5\%) were PUNLMP, 30 (22.4\%) were LG-UC and 98 (73.1\%) were HG-UC. Negative A-FABP immunoreactivity was thus significantly correlated with high grade $(p<0.001)$. The presence of metastatic lymphatic nodes was also correlated with loss of A-FABP expression $(p=0.006)$. In addition, patients whose tumours still expressed A-FABP were on average younger than those with an A-FABP negative tumour: 68.3 vs 72.1 years old $(p=0.028)$. On the other hand, there was no association between A-FABP expression and sex, the presence of visceral metastases or associated Cis. To conclude, A-FABP immunoexpression was significantly associated with the following clinicopathological parameters: age, stage, grade, and lymph node status. Loss of A-FABP expression was generally correlated with high histologic grade and high stage.

\section{Association of clinicopathological data and A-FABP expression with EFS and OS}

An univariate statistical analysis was carried out in patients with UC to correlate EFS and OS with different clinical and histological parameters and with A-FABP expression (Table 2, Fig. 3a and b). During the period of 

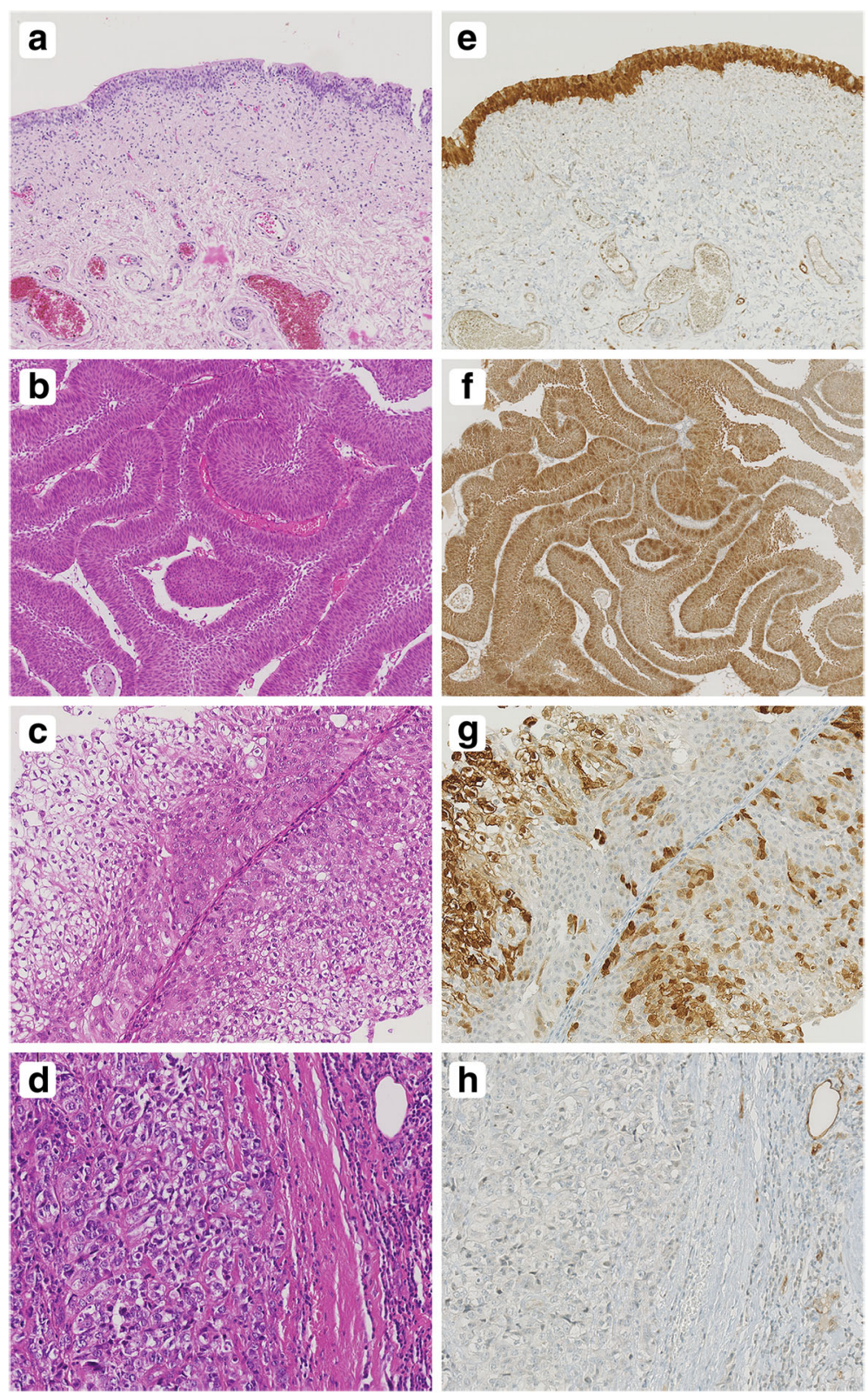

Fig. 2 A-FABP expression in urothelial carcinoma. a-d Representative haematoxylin and eosin (H\&E) staining. e-h A-FABP immunostaining. a Normal urothelium showing strong A-FABP staining in the entire height $(\mathbf{e})$, magnification X10. b Low grade pTa papillary UC with strong A-FABP staining (f), magnification X10. c HG-UC pT1 with patchy A-FABP staining (g), magnification X20. d HG-UC pT3 invasive UC without A-FABP immunostaining (h), magnification $\times 20$

the study, $126(53.4 \%)$ patients presented an event (recurrence, progression, or death) and $110(46.6 \%)$ did not. Younger patients $(\leq 72$ years old) had a longer median EFS (mEFS) than older patients (41.9 months vs 17.5 months; $p=0.005$ ). A longer mEFS was also associated with pTa stage (72.3 months vs 14.8 for pT1 and 15.9 for $\mathrm{pT} 2-4 ; p<0.001)$, the absence of metastatic lymph nodes (34.9 months vs 15.2 months; $p=0.005$ ) as well as with low grade (mEFS not reached for PUNLMP, 35.9 months for LG-UC and 17.5 months for HG-UC; $p$
$=0.002)$. The univariate analysis showed that patients with a papillary tumour had a longer median OS (mOS) (149.3 months vs 33.2 months for patients with a histological variant; $p=0.032$ ). Shorter mOS was associated with high stage pT2-4 (18 months vs 81.3 months for pT1, not reached for pTa; $p<0.001)$, the presence of metastatic lymph nodes (15.2 months vs 154.2 months; $p<0.001)$, the presence of metastases (16.5 months vs 149.3 months; $p<0.001$ ), and high grade (not reached for PUNLMP, 178.5 months for LG-UC and 56.3 months 
Table 2 Univariate and multivariate analyses of clinicopathological data and A-FABP expression in relation to EFS and OS of patients with urothelial carcinoma

\begin{tabular}{|c|c|c|c|c|c|c|c|c|c|c|c|c|c|c|c|c|}
\hline & \multicolumn{4}{|c|}{ Univariate analysis } & \multicolumn{4}{|c|}{ Multivariate analysis } & \multicolumn{4}{|c|}{ Univariate analysis } & \multicolumn{4}{|c|}{ Multivariate analysis } \\
\hline & \multirow[t]{2}{*}{ mEFS } & \multicolumn{2}{|c|}{$95 \% \mathrm{Cl}$} & \multirow[t]{2}{*}{$p$} & \multirow[t]{2}{*}{$H R$} & \multicolumn{2}{|c|}{$95 \% \mathrm{Cl}$} & \multirow[t]{2}{*}{$p$} & \multirow[t]{2}{*}{ mOS } & \multicolumn{2}{|c|}{$95 \% \mathrm{Cl}$} & \multirow[t]{2}{*}{$p$} & \multirow[t]{2}{*}{$\mathrm{HR}$} & \multicolumn{2}{|c|}{$95 \% \mathrm{Cl}$} & \multirow[t]{2}{*}{$p$} \\
\hline & & - & + & & & - & + & & & - & + & & & - & + & \\
\hline \multicolumn{17}{|l|}{ Sex } \\
\hline Male & 29.3 & 17.1 & 41.5 & 0.371 & & & & & 128.4 & 91.9 & 165.0 & 0.696 & & & & \\
\hline Female & 33.2 & 0.0 & 88.0 & & & & & & not reached & & & & & & & \\
\hline \multicolumn{17}{|l|}{ Median Age } \\
\hline$\leq 72$ years & 41.9 & 6.3 & 77.4 & 0.005 & 1.6 & 1.1 & 2.2 & 0.01 & not reached & & & 0.002 & 2.0 & 1.3 & 3.2 & 0.002 \\
\hline$>72$ years & 17.5 & 4.5 & 30.4 & & & & & & 72.3 & 48.0 & 96.6 & & & & & \\
\hline \multicolumn{17}{|l|}{ Histology } \\
\hline Papillary & 30.5 & 14.2 & 46.9 & 0.702 & & & & & 149.3 & 108.1 & 190.5 & 0.032 & & & & \\
\hline Variants & 29.6 & 27.1 & 32.2 & & & & & & 33.2 & 28.1 & 38.2 & & & & & \\
\hline \multicolumn{17}{|l|}{ pT } \\
\hline pTa & 72.3 & 34.8 & 109.8 & $<0.001$ & 1.4 & 1.1 & 1.7 & 0.003 & not reached & & & $<0.001$ & 2.1 & 1.6 & 2.9 & $<0.001$ \\
\hline pT1 & 14.8 & 7.7 & 22.0 & & & & & & 81.3 & 47.1 & 115.5 & & & & & \\
\hline pT2-4 & 15.9 & 11.2 & 20.6 & & & & & & 18.0 & 7.1 & 29.0 & & & & & \\
\hline \multicolumn{17}{|l|}{$\mathrm{pN}$} \\
\hline 0 & 34.9 & 16.5 & 53.2 & 0.005 & & & & & 154.2 & 107.8 & 200.5 & $<0.001$ & 2.1 & 1.1 & 4.0 & 0.028 \\
\hline $1-2$ & 15.2 & 6.7 & 23.7 & & & & & & 15.2 & 6.7 & 23.7 & & & & & \\
\hline \multicolumn{17}{|l|}{$\mathrm{pM}$} \\
\hline 0 & 33.2 & 20.4 & 45.9 & 0.059 & & & & & 149.3 & 110.4 & 188.3 & $<0.001$ & & & & \\
\hline 1 & 16.5 & 3.7 & 29.3 & & & & & & 16.5 & 3.7 & 29.3 & & & & & \\
\hline \multicolumn{17}{|l|}{ Grade } \\
\hline PUNLMP & not reached & & & 0.002 & & & & & not reached & & & $<0.001$ & & & & \\
\hline LG-UC & 35.9 & 7.9 & 63.9 & & & & & & 178.5 & 122.5 & 234.6 & & & & & \\
\hline HG-UC & 17.5 & 10.2 & 24.8 & & & & & & 56.3 & 25.6 & 87.1 & & & & & \\
\hline \multicolumn{17}{|l|}{ Cis } \\
\hline no & 30.5 & 19.1 & 42.0 & 0.258 & & & & & 128.7 & 89.4 & 167.9 & 0.789 & & & & \\
\hline yes & 81.3 & 0 & 181.4 & & & & & & 81.3 & 0 & 166.4 & & & & & \\
\hline \multicolumn{17}{|l|}{$A-F A B P$} \\
\hline negative & 17.5 & 9.9 & 25.0 & 0.001 & & & & & 76.7 & 50.0 & 103.5 & 0.009 & & & & \\
\hline positive & 62.5 & 1.8 & 123.2 & & & & & & 154.2 & 114.9 & 193.4 & & & & & \\
\hline
\end{tabular}

Abbreviations: EFS Event-free survival, OS Overall survival, PUNLMP Papillary urothelial neoplasm of low malignant potential, LG-UC Low grade urothelial carcinoma, HG-UC High grade urothelial carcinoma, Cis In situ carcinoma

for HG-UC; $p<0.001)$. Importantly, patients whose UC still expressed A-FABP had longer EFS (62.5 vs 17.5 months, respectively; $p=0.001)$ as well as longer OS (154.2 vs 76.7 months; $p=0.009$ ) than those whose UC were A-FABP negative. A-FABP positive expression is an indicator of a good prognosis for the clinical outcome of patients with NMIBC (pTa/pT1). It could be a suitable tool for clinicians to distinguish patients with NMIBC who will progress from those who will not.

We performed a multivariate analysis including significant parameters of the univariate analysis (age, stage, lymph node status, grade and A-FABP expression). The multivariate Cox model applied to the resulting parameters showed that age ( $\geq 72$ years) and stage could be considered as independent prognostic factors for EFS ( $p=$ 0.01 and $p=0.003$, respectively) as well as age, stage and lymph node status for OS $(p=0.002, p<0.001$ and $p=$ 0.028 , respectively). A-FABP expression was not recognised as an independent significant prognostic marker.

\section{Association of clinicopathological data and A-FABP expression with RFS and PFS in pTa and pT1 tumours} Table 3 gives the results of RFS and PFS using univariate Cox analysis. Kaplan-Meier curves were plotted 

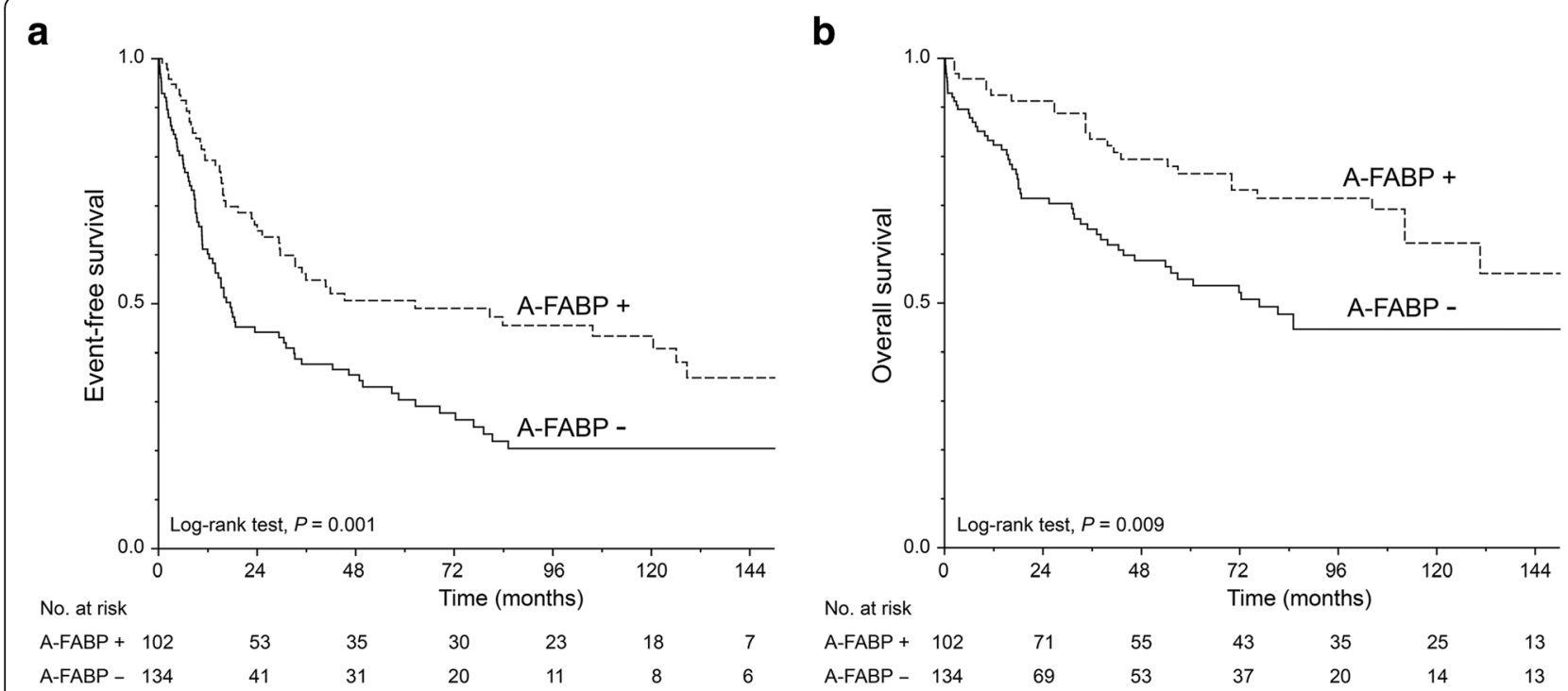

Fig. 3 Kaplan-Meier plots for negative and positive A-FABP expression in the overall cohort. a Event-free survival, b Overall survival

Table 3 Univariate analysis of clinicopathological data and A-FABP expression in relation to RFS and PFS of patients with NMIBC

\begin{tabular}{|c|c|c|c|c|c|c|c|c|}
\hline & \multirow[t]{3}{*}{$\mathrm{HR}$} & \multirow{2}{*}{\multicolumn{2}{|c|}{$\frac{\mathrm{RFS}}{95 \% \mathrm{Cl}}$}} & \multirow[t]{3}{*}{$P$} & \multirow[t]{3}{*}{$H R$} & \multirow{2}{*}{\multicolumn{2}{|c|}{$\frac{\text { PFS }}{95 \% \mathrm{Cl}}$}} & \multirow[t]{3}{*}{$P$} \\
\hline & & & & & & & & \\
\hline & & - & + & & & - & + & \\
\hline \multicolumn{9}{|l|}{$\mathrm{pTa}$} \\
\hline $\operatorname{Sex}(F)$ & 0.60 & 0.24 & 1.53 & 0.280 & 0.04 & 0.00 & 22.1 & 0.111 \\
\hline Age $(>72)$ & 1.21 & 0.65 & 2.28 & 0.547 & 1.16 & 0.38 & 3.54 & 0.800 \\
\hline Histology (variants) & 0.99 & 0.14 & 7.26 & 0.997 & 0.05 & 0.00 & $404,941.26$ & 0.574 \\
\hline Grade (for each change of category) & 1.14 & 0.71 & 1.83 & 0.564 & 1.27 & 0.54 & 2.99 & 0.763 \\
\hline Cis (yes) & & & & NA & & & & NA \\
\hline A-FABP negativity & 0.55 & 0.3 & 1.02 & 0.055 & 0.34 & 0.10 & 0.97 & 0.045 \\
\hline \multicolumn{9}{|l|}{ pT1 } \\
\hline $\operatorname{Sex}(F)$ & 0.04 & 0.00 & 16.09 & 0.102 & 4.34 & 0.41 & 46.4 & 0.187 \\
\hline Age $(>72)$ & 2.04 & 0.84 & 5.00 & 0.110 & 0.75 & 0.12 & 4.6 & 0.756 \\
\hline Histology (variants) & 0.04 & 0.00 & 129.34 & 0.245 & 0.05 & 0.00 & $18,539,252.39$ & 0.646 \\
\hline Grade (for each change of category) & 0.58 & 0.17 & 1.96 & 0.373 & 25.34 & 0.00 & $2,740,610.19$ & 0.392 \\
\hline Cis (yes) & 0.03 & 0.00 & 3.65 & 0.151 & 0.04 & 0.00 & 1840.31 & 0.350 \\
\hline A-FABP negativity & 1.22 & 0.51 & 2.91 & 0.648 & 0.39 & 0.04 & 3.48 & 0.380 \\
\hline \multicolumn{9}{|l|}{$\mathrm{pTa} / \mathrm{pT} 1$} \\
\hline $\operatorname{Sex}(F)$ & 0.43 & 0.17 & 1.09 & 0.074 & 0.38 & 0.05 & 2.86 & 0.347 \\
\hline Age $(>72)$ & 1.52 & 0.92 & 2.51 & 0.104 & 1.01 & 0.39 & 2.63 & 0.976 \\
\hline Histology (variants) & 0.48 & 0.07 & 3.47 & 0.468 & 0.05 & 0.00 & $11,861.4$ & 0.631 \\
\hline Stage (pT1) & 1.71 & 1.01 & 2.9 & 0.048 & 1.06 & 0.38 & 2.99 & 0.907 \\
\hline Grade (for each change of category) & 1.28 & 0.89 & 1.83 & 0.183 & 1.27 & 0.65 & 2.48 & 0.487 \\
\hline Cis (yes) & 0.05 & 0.00 & 5.19 & 0.201 & 1.3 & 0.17 & 9.79 & 0.797 \\
\hline A-FABP negativity & 0.66 & 0.40 & 1.08 & 0.099 & 0.36 & 0.13 & 0.96 & 0.041 \\
\hline
\end{tabular}

*Abbreviations: NMIBC (pTa and pT1) Non-muscle invasive bladder cancer, Cl Confidence interval, HR Hazard ratio, RFS Recurrence-free survival, PFS Progression-free survival 


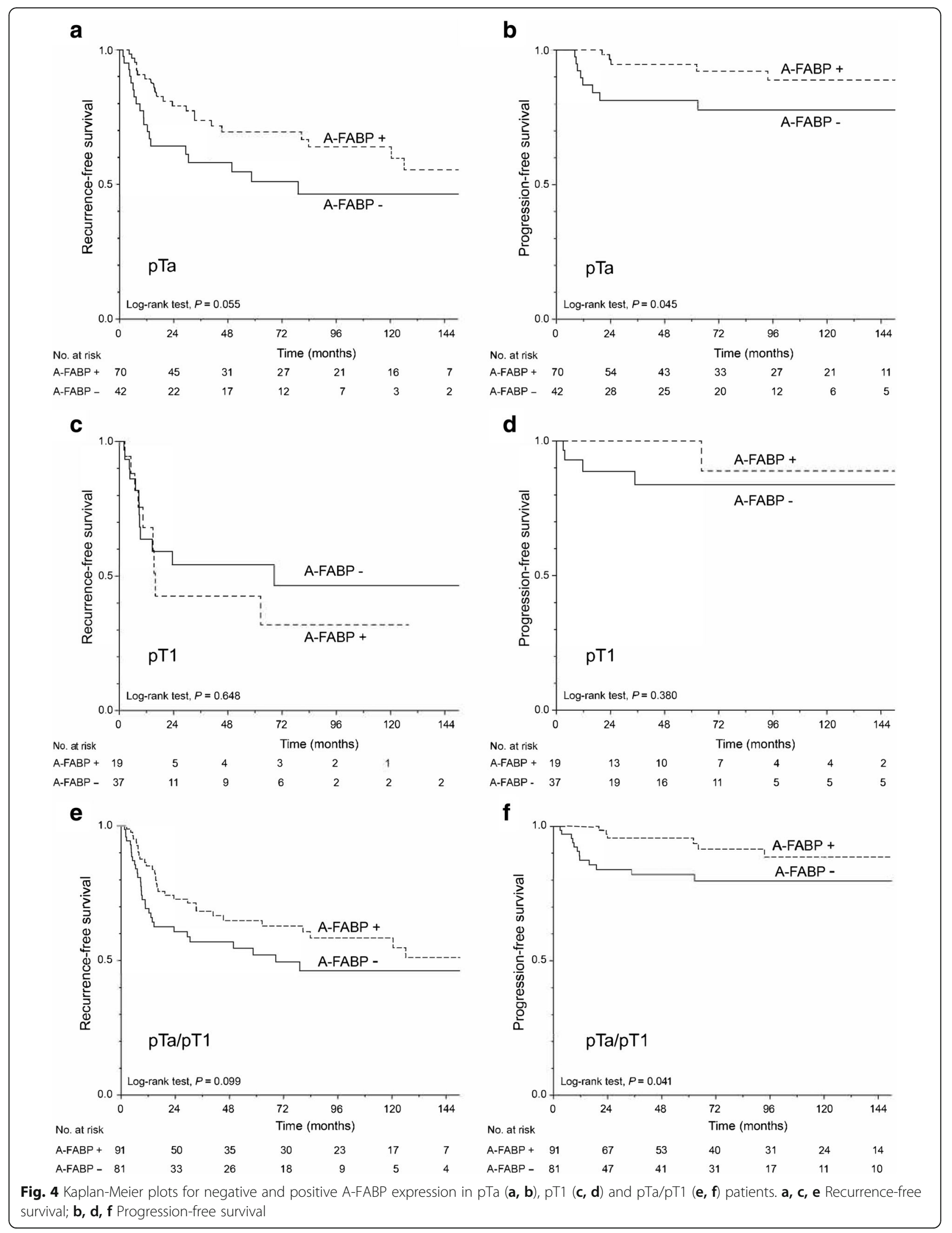


according to A-FABP expression (Fig. 4) in the pTa, pT1 and $\mathrm{pTa} / \mathrm{pT} 1$ UC. Sex, age, histology of the tumour, grade, and Cis were not associated with RFS or PFS. On the other hand, pT1 tumours had a higher risk of recurrence than $\mathrm{pTa}(\mathrm{HR}, 1.71 ; 95 \% \mathrm{CI}, 1.01-2.90 ; p=0.048)$. Patients treated for pTa tumours with negative expression of A-FABP had a higher risk of progression (HR, 0.34; 95\% CI, $0.10-0.97 ; p=0.045)$. The risk of progression was not significant in pT1 UC patients with a negative expression of A-FABP. Patients in $\mathrm{pTa} / \mathrm{pT} 1$ group with negative expression of A-FABP had a higher risk of progression (HR, 0.36; 95\% CI, 0.13-0.96; $p=0.041$ ).

\section{Discussion}

Non-muscle invasive bladder cancers are a heterogeneous group of urothelial tumours displaying the complexity of molecular alterations during bladder carcinogenesis. Significant progression risk factors currently highlighted are the presence of Cis, pT1G3 tumours, multifocal carcinoma and lymph node status [28, 29]. Nevertheless, these histopathological parameters cannot forecast the long-term outcome of bladder cancer. It is therefore urgent to develop and validate in clinical practice useful prognostic and predictive biomarkers in order to identify patients at high risk of progression.

In the present work, we focused our attention on the A-FABP protein. We evaluated by immunohistochemistry the association of A-FABP status with clinicopathological features and prognostic outcomes in patients with UC. We confirmed the high expression of this protein in healthy urothelium, as previously described $[24,25]$. We demonstrated that loss of A-FABP expression was correlated with more advanced age, the presence of metastatic lymph nodes, and, most importantly, with high tumour stage and histological grade. Another study examined A-FABP expression by immunohistochemistry [25]. The authors classified the immunostaining into six types according to its intensity and distribution. However, in clinical practice, these types are not easily applicable. For this reason, we proposed assessing positivity according to threshold and intensity of A-FABP staining. We considered as positive a moderate or strong staining of more than $10 \%$ of tumour cells, which was easy to use in routine. In our study, A-FABP staining in most cases was both nuclear and cytoplasmic, and in the majority immunostaining was strong. We also studied the heterogeneity of immunostaining as follows: absent, patchy, basal cell layer only, one-third, two-thirds, or the entire height of the urothelium. A-FABP positive tumours could simultaneously express different types of staining in the studied area. However, in most cases, the entire height of the urothelium was involved and showed patchy staining (data not shown).

In our work, survival analyses (EFS and OS) showed that the prognosis of bladder cancer depended on age, stage, grade and metastatic lymph node status. While the presence of Cis is recognised to be a factor of poor prognosis, we failed to confirm this. This is probably due to the low number of $\mathrm{Cis}$ in our cohort, perhaps because TURB essentially involved papillary tumours. In addition, the univariate survival analysis showed that A-FABP positivity was associated with a better prognosis for EFS and OS. However, we failed to identify A-FABP as an independent factor in the multivariate analysis. Finally, our data demonstrated that the presence of A-FABP was predictive of the absence of any event (recurrence, progression or death) and that loss of A-FABP expression in resected primary $\mathrm{pTa} \mathrm{UC}$, and $\mathrm{pTa} / \mathrm{pT} 1$ group was a higher risk factor of progression. The decrease of A-FABP protein level may be used to precisely identify subsets of patients with NMIBC that have a poorer prognosis.

A-FABP has attracted increasing interest in recent years. Several studies have identified high serum levels of this protein as a useful prognostic marker for metabolic disorders, such as obesity, metabolic syndrome, type 2 diabetes and atherosclerosis [30-33]. While A-FABP was initially described in adipocytes and macrophages, the expression of this protein has currently been demonstrated in different cell types and in particular in some tumours. Nevertheless, the role of A-FABP in cancer is controversial. It could act either as a tumour suppressor or as an oncogene depending on tumour type. Thus, contrary to what we have demonstrated in bladder cancer, where strong expression of A-FABP was associated with a good prognosis, high A-FABP expression was significantly associated with shorter disease-free survival and OS in breast cancer patients [18]. In NSCLC, it was correlated with higher TNM stage and associated with shorter overall survival, and was an independent poor prognostic factor [23]. Up-regulation of A-FABP expression has been reported in metastatic human ovarian cancer compared with primary ovarian tumours [20]. An immunohistochemical study carried out in squamous cell carcinomas showed, in the same tissue sample, significantly higher expression of A-FABP in the tumour area of tongue SCC than in the non-tumour area. In addition, the protein knock-down with a specific siRNA prevented the proliferation of several SCC cell lines [22]. Overexpression of FABP4 has also been reported in glioblastoma [34].

On the other hand, other studies showed similar results to those we observed in UC. Lower expression of A-FABP was observed in human prostate cancer compared with normal prostate epithelial cells [35]. In the same way, A-FABP was detected in normal liver cells but not in hepatoma cells [36]. Different studies have examined mRNA and protein expression profiles in normal bladder urothelium and in UC with various 
histopathological grades and stages using diverse technical approaches (two-dimensional polyacrylamide gel electrophoresis, microsequencing, mass spectrometry, two-dimensional gel protein database approach for polypeptide identification, tissue microarray, immunohistochemistry, RT-PCR). All of these investigations revealed downregulation of A-FABP in invasive UC [24, 25], and good association of loss of A-FABP with tumour stage and grade [25]. In a previous study, we also reported that the decrease of $a$-fabp transcript level was significantly associated with high tumour stage and histological grade [27]. In addition, 2D-PAGE and RT-PCR analyses showed that protein abundancy was correlated with $a-f a b p$ mRNA levels, indicating that A-FABP expression was regulated transcriptionally or post-transcriptionally rather than at the translational level [37]. EFS, OS, RFS as well as PFS were not analysed in these studies.

Unlike the studies described above reporting the expression of A-FABP protein by immunohistochemical or two-dimensional electrophoresis analyses, we show on a long-term follow-up of patients that high expression of A-FABP was associated with a good prognosis and that the decrease of A-FABP expression is a tumor progression marker of $\mathrm{pTa}$ and $\mathrm{pTa} / \mathrm{pT} 1$ group. Our study has attributed a prognostic value to the diminution of A-FABP. Another argument indicating that the absence of A-FABP could favour tumour progression is the elevated expression of the $a-f a b p$ gene observed in a non-Cis group of tumours compared with a group with adjacent $\mathrm{Cis}$ [38]. The mechanisms underlying the loss of A-FABP expression in UC have yet to be elucidated. Several hypotheses can be put forward based on the data in the literature, such as a polymorphism or epigenetic modifications. In triple-negative breast cancer, a single nucleotide polymorphism (SNP) of the 3'-UTR region of $a-f a b p$ gene has been shown to be associated with significantly lower expression of the protein [39]. The authors suggest that this SNP could distinguish the patients with high risk of recurrence. The alteration of DNA methylation patterns has been linked to carcinogenesis. In particular, hypermethylation was associated with tumour suppressor gene silencing [40]. This epigenetic modification is under the control of the DNA methyltransferases (DNMT). Thus, hypermethylation of the $\mathrm{CpG}$ islands around the human FABP4 promoter could be involved in the loss of FABP4 expression. Increased DNMT1 expression has been reported in human transitional cell carcinoma of the bladder. Interestingly, protein expression was higher in flat carcinoma in situ. Increased DNMT1 expression was also significantly correlated with histological grade [41].

It should be noted that the results of the present study are in contradiction with those of Wild et al. which found that high FABP4 expression was associated with
p'Ta UC progression [42]. These authors demonstrated that FABP4 expression was up-regulated in 17 of $21 \mathrm{pTa}$ samples with progression and down-regulated in 21 of 24 pTa tumours without progression. However, this study was carried out on mRNA by a combination of laser microdissection and gene expression profiling, and it was not validated by immunohistochemistry.

\section{Conclusions}

In our pathological practice, A-FABP could be a helpful prognostic marker for bladder UC, easy to detect on formalin-fixed paraffin embedded tumour sections. Importantly, we demonstrated that loss of A-FABP expression was predictive of a higher risk of progression in $\mathrm{pTa}$ UC. This risk was not significant in pT1 and significant in the pTa/pT1 UC group. Bladder cancer is one of the most expensive to manage due to active surveillance following treatment of NMIBC. The identification of progression predictors is of great importance for the clinician in order to propose appropriate treatment and to improve the management of clinical follow-up of patients. Further prospective studies should be started to establish whether closer follow-up might be beneficial for patients with pT1 UC expressing low level or no A-FABP. Such follow-up could identify as early as possible patients at risk of progression. The surveillance strategy should be strengthened and more aggressive adjuvant therapy should be performed after initial curative surgery to achieve better prognosis. Immunohistochemical analysis of biomarkers on diagnostic biopsies is used in hospital routine for prognosis. In future perspectives, it could be interesting to study the prognostic value of this new biomarker on circulating A-FABP and/or urine A-FABP testing. This could be an easier way to follow the patients. In vitro functional studies are needed to elucidate the role of A-FABP in bladder cancer carcinogenesis. Highlighting the different signalling pathways controlling A-FABP expression is crucial to impact these regulatory networks involved in the disease. Given the results we have shown, we could postulate that maintaining a high level of A-FABP could prevent tumour progression. This protein is a target of PPAR and is induced by PPAR activators, as we have previously reported [27]. A pharmacological strategy using intravesical instillations of PPAR agonists could be applied to induce FABP4 expression in order to prevent tumour progression.

\section{Abbreviations}

2D-PAGE: two dimensional-polyacrylamide gel electrophoresis; AFABP: Adipocyte-fatty acid binding proein; BSA: Bovine serum albumin; Cl: Confidence interval; Cis: Carcinoma in situ; DAB: 3-3'-diaminobenzidine; DNMT: DNA methyltransferase; EDTA: Ethylenediaminetetraacetic acid; EFS: Event-free survival; HES: Harris haematoxylin eosine safran; HG-UC: Highgrade-urothelial carcinoma; HR: Hazard ratio; HRP: Horse radish peroxidase; IHC: Immunohistochemistry; ISH: In situ hybridization; LG-UC: Low grade- 
urothelial carcinoma; MIBC: Muscle invasive bladder cancer; NMIBC: Nonmuscle invasive bladder cancer; NSCLC: Non small cell lung carcinoma; OS: Overall survival; PBS: Phosphate buffered saline; PFS: Progression-free survival; PPARY: Peroxisome proliferator-activated receptor $\gamma_{\text {; }}$ PUNLMP: Papillary urothelial neoplasm of low malignant potential; RFS: Recurrence-free survival; RIPA: Radioimmunoprecipitation assay; RTPCR: Reverse transcription-polymerase chain reaction; SCC: Squamous cell carcinoma; SDS-PAGE: Sodium dodecylsulfate-polyacrylamide gel electrophoresis; SNP: Single nucleotide polymorphism; TBS: Tris-buffered saline; TNM: Tumour node matastasis; TURB: Transurethral resection of bladder tumour; UC: Urothelial carcinoma; WHO: World Health Organization

\section{Acknowledgements}

We thank all the technicians of the pathology department for technical assistance in this study. Tissue samples were provided by the biobank BB0033-00024 "Tumorothèque Régionale de Franche-Comté (TRFC)".

\section{Funding}

This study was supported by research grants from the Ligue Nationale contre le Cancer (CCIR-GE) and the Région Bourgogne Franche-Comté. The funders allowed the authors to perform this study. They did not participate in the study design, data collection, analysis or interpretation. They had no role in the decision to publish or preparation of the manuscript.

\section{Availability of data and materials}

All data generated or analysed during this study are included in this published article.

\section{Authors' contributions}

IL, SF and SVD planned the study and drafted the manuscript. CM collected the clinical, epidemiological and histological data, interpreted the results and wrote the manuscript. IB analysed the results. FM conducted the statistical analysis. IL, SF, HB, FK and SVD were involved in interpreting the results and critically revising the manuscript. All authors read and approved the final version.

\section{Ethics approval and consent to participate}

Ethical approval for this project was obtained from the CPP - Est II, the ethics committee of our institution. All procedures performed in this study involving human participants were thus in accordance with the ethical standards of the institutional and/or national research committee and with the 1964 Helsinki declaration and its later amendments or comparable ethical standards. All patients gave written consent to participation in the study.

\section{Consent for publication}

Not applicable.

\section{Competing interests}

The authors declare that they have no competing interests.

\section{Publisher's Note}

Springer Nature remains neutral with regard to jurisdictional claims in published maps and institutional affiliations.

\section{Author details \\ ${ }^{1}$ Department of Pathology, University Hospital of Besançon, F-25000 Besançon, France. 'University Bourgogne Franche-Comté, EA3181, LabEx LipSTIC ANR-11-LABX-0021, F-25030 Besançon, France. ${ }^{3}$ Department of Urology, University Hospital of Besançon, F-25000 Besançon, France.}

Received: 20 July 2018 Accepted: 26 November 2018

\section{Published online: 10 December 2018}

\section{References}

1. Antoni S, Ferlay J, Soerjomataram I, Znaor A, Jemal A, Bray F. Bladder cancer incidence and mortality: a global overview and recent trends. Eur Urol. 2016;71:96-08

2. Montironi R, Lopez-Beltran A, Scarpelli M, Mazzucchelli R, Cheng L. Morphological classification and definition of benign, preneoplastic and non-invasive neoplastic lesions of the urinary bladder. Histopathology. 2008; 53:621-33.

3. Gospodarowicz MK, Mason M. Urological Tumours. In: Brierley DJ, Gospodarowicz MK, Wittekind C, editors. TNM Classification of Malignant Tumors. 8th ed. Oxford: Wiley; 2017. p. 204-7.

4. Epstein Jl, Amin MB, Reuter VR, Mostofi FK. The World Health Organization/ International Society of Urological Pathology consensus classification of urothelial (transitional cell) neoplasms of the urinary bladder. Bladder Consensus Conference Committee. Am J Surg Pathol. 1998;22:1435-48.

5. Babjuk M, Burger M, Zigeuner R, Shariat SF, Van Rhijn BW, Compérat E, Sylvester RJ, Kaasinen E, Böhle A, Palou Redorta J, Rouprêt M. European Association of Urology. EAU guidelines on non-muscle-invasive urothelial carcinoma of the bladder: update 2013. Eur Urol. 2013;64:639-53.

6. Droller MJ. Markers in bladder cancer--issues to consider. J Urol. 1998;160: 2009-10.

7. Knowles MA, Hurst CD. Molecular biology of bladder cancer: new insights into pathogenesis and clinical diversity. Nat Rev Cancer. 2015;15:25-41.

8. Sinha P, Hütter G, Köttgen E, Dietel M, Schadendorf D, Lage H. Increased expression of epidermal fatty acid binding protein, cofilin, and 14-3-3-sigma (stratifin) detected by two-dimensional gel electrophoresis, mass spectrometry and microsequencing of drug-resistant human adenocarcinoma of the pancreas. Electrophoresis. 1999;20:2952-60.

9. Hammamieh R, Chakraborty N, Bermada M, Das R, Jett M. Expression patterns of fatty acid binding proteins in breast cancer cells. J Exp Ther Oncol. 2005;5:133-43.

10. Ohmachi T, Inoue H, Mimori K, Tanaka F, Sasaki A, Kanda T, Fujii H, Yanaga K, Mori M. Fatty acid binding protein 6 is overexpressed in colorectal cancer. Clin Cancer Res. 2006;12:5090-5.

11. Teratani T, Domoto T, Kuriki K, Kageyama T, Takayama T, Ishihawa A, Ozono S, Nozawa R. Detection of transcript for brain-type fatty acidbinding protein in tumor and urine of patients with renal cell carcinoma. Urology. 2007;69:236-40.

12. Slipicevic A, Jorgensen $K$, Skrede M, Rosnes AK, Troen G, Davidson B, Florenes VA. The fatty acid binding protein 7 (FABP7) is involved in proliferation and invasion of melanoma cells. BMC Cancer. 2008;8:276.

13. Kawaguchi K, Senga S, Kubota C, Kawamura Y, Ke Y, Fujii H. High expression of fatty acid-binding protein 5 promotes cell growth and metastatic potential of colorectal cancer cells. FEBS Open Bio. 2016;11:190-9.

14. Furuhashi M, Hotamisligil GS. Fatty acid-binding proteins: role in metabolic diseases and potential as drug targets. Nat Rev Drug Discov. 2008;7:489-03.

15. Hotamisligil GS, Bernlohr DA. Metabolic functions of FABPs--mechanisms and therapeutic implications. Nat Rev Endocrinol. 2015;11:592-05.

16. Furuhashi M, Saitoh S, Shimamoto K, Miura T. Fatty acid-binding protein 4 (FABP4): pathophysiological insights and potent clinical biomarker of metabolic and cardiovascular diseases. Clin Med Insights Cardiol. 2014;8:23-33.

17. Tan NS, Shaw NS, Vinckenbosch N, Liu P, Yasmin R, Desvergne B, Wahli W, Noy N. Selective cooperation between fatty acid binding proteins and peroxisome proliferator-activated receptors in regulating transcription. Mol Cell Biol. 2002:22:5114-27 Erratum in: Mol Cell Biol 22:6318.

18. Hancke K, Grubeck D, Hauser N, Kreienberg R, Weiss JM. Adipocyte fatty acid-binding protein as a novel prognostic factor in obese breast cancer patients. Breast Cancer Res Treat. 2010;119:367-77.

19. Kim S, Lee Y, Koo JS. Differential expression of lipid metabolism-related proteins in different breast cancer subtypes. PLoS One. 2015;10:e0119473.

20. Nieman KM, Kenny HA, Penicka CV, Ladanyi A, Buell-Gutbrod R, Zillhardt MR, Romero IL, Carey MS, Mills GB, Hotamisligil GS, Yamada SD, Peter ME, Gwin $\mathrm{K}$, Lengyel E. Adipocytes promote ovarian cancer metastasis and provide energy for rapid tumor growth. Nat Med. 2011;17:1498-503.

21. Tucker SL, Gharpure K, Herbrich SM, Unruh AK, Nick AM, Crane EK, Coleman RL, Guenthoer J, Dalton HJ, Wu SY, Rupaimoole R, Lopez-Berestein G, Ozpolat B, Ivan C, Hu W, Baggerly KA, Sood AK. Molecular biomarkers of residual disease after surgical debulking of high-grade serous ovarian cancer. Clin Cancer Res. 2014;20:3280-8.

22. Lee D, Wada K, Taniguchi Y, Al-Shareef H, Masuda T, Usami Y, Aikawa T, Okura M, Kamisaki Y, Kogo M. Expression of fatty acid binding protein 4 is involved in the cell growth of oral squamous cell carcinoma. Oncol Rep. 2014:31:1116-20.

23. Tang Z, Shen Q, Xie H, Zhou X, Li J, Feng J, Liu H, Wang W, Zhang S, $\mathrm{Ni}$ S. Elevated expression of FABP3 and FABP4 cooperatively correlates with poor prognosis in non-small cell lung cancer (NSCLC). Oncotarget. 2016;7:46253-62. 
24. Celis JE, Ostergaard M, Basse B, Celis A, Lauridsen JB, Ratz GP, Andersen I, Hein B, Wolf H, Orntoft TF, Rasmussen HH. Loss of adipocyte-type fatty acid binding protein and other protein biomarkers is associated with progression of human bladder transitional cell carcinomas. Cancer Res. 1996;56:4782-90.

25. Ohlsson G, Moreira JM, Gromov P, Sauter G, Celis JE. Loss of expression of the adipocyte-type fatty acid-binding protein (A-FABP) is associated with progression of human urothelial carcinomas. Mol Cell Proteomics. 2005;4:570-81.

26. Celis A, Rasmussen HH, Celis P, Basse B, Lauridsen JB, Ratz G, Hein B, Ostergaard M, Wolf H, Orntoft T, Celis JE. Short-term culturing of low-grade superficial bladder transitional cell carcinomas leads to changes in the expression levels of several proteins involved in key cellular activities. Electrophoresis. 1999;20:355-61.

27. Boiteux G, Lascombe I, Roche E, Plissonnier ML, Clairotte A, Bittard H, Fauconnet S. A-FABP, a candidate progression marker of human transitional cell carcinoma of the bladder, is differentially regulated by PPAR in urothelial cancer cells. Int J Cancer. 2009;124:1820-8.

28. Sylvester RJ, van der Meijden AP, Oosterlinck W, Witjes JA, Bouffioux C, Denis L, Newling DW, Kurth K. Predicting recurrence and progression in individual patients with stage ta $\mathrm{T} 1$ bladder cancer using EORTC risk tables: a combined analysis of 2596 patients from seven EORTC trials. Eur Urol. 2006;49:466-75 discussion 475-7.

29. Van Rhijn BW, Burger M, Lotan Y, Solsona E, Stief CG, Sylvester RJ, Witjes JA, Zlotta AR. Recurrence and progression of disease in nonmuscle-invasive bladder cancer: from epidemiology to treatment strategy. Eur Urol. 2009;56:430-42.

30. Xu A, Wang Y, Xu JY, Stejskal D, Tam S, Zhang J, Wat NM, Wong WK, Lam KS. Adipocyte fatty acid-binding protein is a plasma biomarker closely associated with obesity and metabolic syndrome. Clin Chem. 2006;52:405-13.

31. Aragonès G, Ferré R, Lázaro I, Cabré A, Plana N, Merino J, Heras M, Girona J, Masana L. Fatty acid-binding protein 4 is associated with endothelial dysfunction in patients with type 2 diabetes. Atherosclerosis. 2010;213:329-31.

32. Cabré A, Babio N, Lázaro I, Bulló M, Garcia-Arellano A, Masana L, SalasSalvadó J. FABP4 predicts atherogenic dyslipidemia development. The PREDIMED study. Atherosclerosis. 2012;222:229-34.

33. Cooke AA, Connaughton RM, Lyons CL, McMorrow AM, Roche HM. Fatty acids and chronic low grade inflammation associated with obesity and the metabolic syndrome. Eur J Pharmacol. 2016;785:207-14.

34. Cataltepe O, Arikan MC, Ghelfi E, Karaaslan C, Ozsurekci Y, Dresser K, Li Y, Smith TW, Cataltepe S. Fatty acid binding protein 4 is expressed in distinct endothelial and non-endothelial cell populations in glioblastoma: FABP4 expression in GBM. Neuropathol Appl Neurobiol. 2012;38:400-10.

35. Das R, Hammamieh R, Neill R, Melhem M, Jett M. Expression pattern of fatty acid-binding proteins in human normal and cancer prostate cells and tissues. Clin Cancer Res. 2001;7:1706-15.

36. Yu LR, Zeng R, Shao XX, Wang N, Xu YH, Xia QC. Identification of differentially expressed proteins between human hepatoma and normal liver cell lines by two-dimensional electrophoresis and liquid chromatography-ion trap mass spectrometry. Electrophoresis. 2000;21:3058-68.

37. Gromova I, Gromov P, Wolf H, Celis JE. Protein abundancy and mRNA levels of the adipocyte-type fatty acid binding protein correlate in non-invasive and invasive bladder transitional cell carcinomas. Int J Oncol. 1998;13:379-83.

38. Dyrskjøt L, Kruhøffer M, Thykjaer T, Marcussen N, Jensen JL, Møller K, Ørntoft TF. Gene expression in the urinary bladder: a common carcinoma in situ gene expression signature exists disregarding histopathological classification. Cancer Res. 2004;64:4040-8.

39. Wang W, Yuan P, Yu D, Du F, Zhu A, Li Q, Zhang P, Lin D, Xu B. A singlenucleotide polymorphism in the 3'-UTR region of the adipocyte fatty acid binding protein 4 gene is associated with prognosis of triple-negative breast cancer. Oncotarget. 2016;7:18984-98.

40. Kagohara LT, Stein-O'Brien GL, Kelley D, Flam E, Wick HC, Danilova LV, Easwaran H, Favorov AV, Qian J, Gaykalova DA, Fertig EJ. Epigenetic regulation of gene expression in cancer: techniques, resources and analysis. Brief Funct Genomics. 2018;17:49-63.

41. Nakagawa T, Kanai Y, Saito Y, Kitamura T, Kakizoe T, Hirohashi S. Increased DNA methyltransferase 1 protein expression in human transitional cell carcinoma of the bladder. J Urol. 2003;170:2463-6.

42. Wild PJ, Herr A, Wissmann C, Stoehr R, Rosenthal A, Zaak D, Simon R, Knuechel R, Pilarsky C, Hartmann A. Gene expression profiling of progressive papillary noninvasive carcinomas of the urinary bladder. Clin Cancer Res. 2005;11:4415-29.

Ready to submit your research? Choose BMC and benefit from:

- fast, convenient online submission

- thorough peer review by experienced researchers in your field

- rapid publication on acceptance

- support for research data, including large and complex data types

- gold Open Access which fosters wider collaboration and increased citations

- maximum visibility for your research: over $100 \mathrm{M}$ website views per year

At BMC, research is always in progress.

Learn more biomedcentral.com/submissions 